\title{
Mathematical Game Theory in Civil Engineering Fire Safety
}

\author{
Olga Shikuskaya ${ }^{1 *}$, Galina Abuova ${ }^{1}$, Ivan Vatunskiy ${ }^{1}$ and Mikhail Shikulskiy ${ }^{2}$ \\ ${ }^{1}$ Astrakhan state university of architecture and civil engineering, Department of fire safety and water \\ use, 414056, Tatischeva str., 18, Astrakhan, Russia \\ 2 Astrakhan state technical university, department of applied informatics in economy, 414056, \\ Tatischeva str., 16, Astrakhan, Russia
}

\begin{abstract}
In the analysis of the project documentation of a twostoreyed sports complex it was established that despite compliance of the project to all standards in the fire safety field, under certain conditions there is a danger of a delay of full people evacuation from the gym room in case of fire that can entail people's death. For the purpose of ensuring fire safety several versions of spaceplanning decisions were considered. The scientific literature analysis showed efficiency of game theory use in the field of fire safety, however in the field of fire safety in construction it was not applied yet. Game theory Application (games with the nature in the conditions of uncertainty) for the revealed problem solution was proved. Three possible scenarios of emergence and development of the fire and four alternative space-planning decisions were considered. For all development scenarios of the fire time of critical values achievement of dangerous fire factors was defined. All necessary evacuation schemes are made and calculations are executed. On the calculated parameters basis the payoff matrix was constructed. An optimal variant of space-planning decisions was chosen. Research results showed expediency and efficiency of game theory application in the field of fire safety in construction.
\end{abstract}

\section{Introduction}

The fire is a process of uncontrollable burning which can cause death, threat of life and to human health and also damage of material values. At the fire, the most important task of firefighters is rescue of people. Their timely evacuation which success depends not only on the coordinated and competent actions of firefighters is important for rescue of people. The set of factors influences over the period of evacuation of people: the number of the evacuated people; planning of the room; quantity and width of doorways; initial location of people, place of ignition, etc.

\footnotetext{
* Corresponding author: shikul@mail.ru
} 
From the moment of the beginning of the fire there passes certain time after which indoors there are dangerous fire factors (DFF): high temperature of the environment, smoke, toxic products of burning, etc., and from this point indoors appears threat of life and to human health. Therefore, time of evacuation has to be less time of approach of dangerous factors of the fire, i.e. the condition has to be met:

$$
t_{\text {'evacuation }} \leq t_{\text {'DFF }}
$$

Evacuation is timed by a technique [1, appendix 2], and calculation of time of approach of dangerous fire factors is made agrees [2].

In the analysis of the project documentation of a two-storeyed sports complex on the basis of the techniques stated above by authors it is established that, despite compliance of the project to all standards in the field of fire safety, there is a probability of nonperformance of a condition (1) at evacuation of people from the room of the gym in a case fire emergence.

Statement of the problem:

In the gym (fig. 1) there are 200 people (the audience, players in the field, judges, etc.). In case of fire alarm all people have to be evacuated before OFP.

The entry condition is defined on the basis of the scheme of the gym (fig. 1).

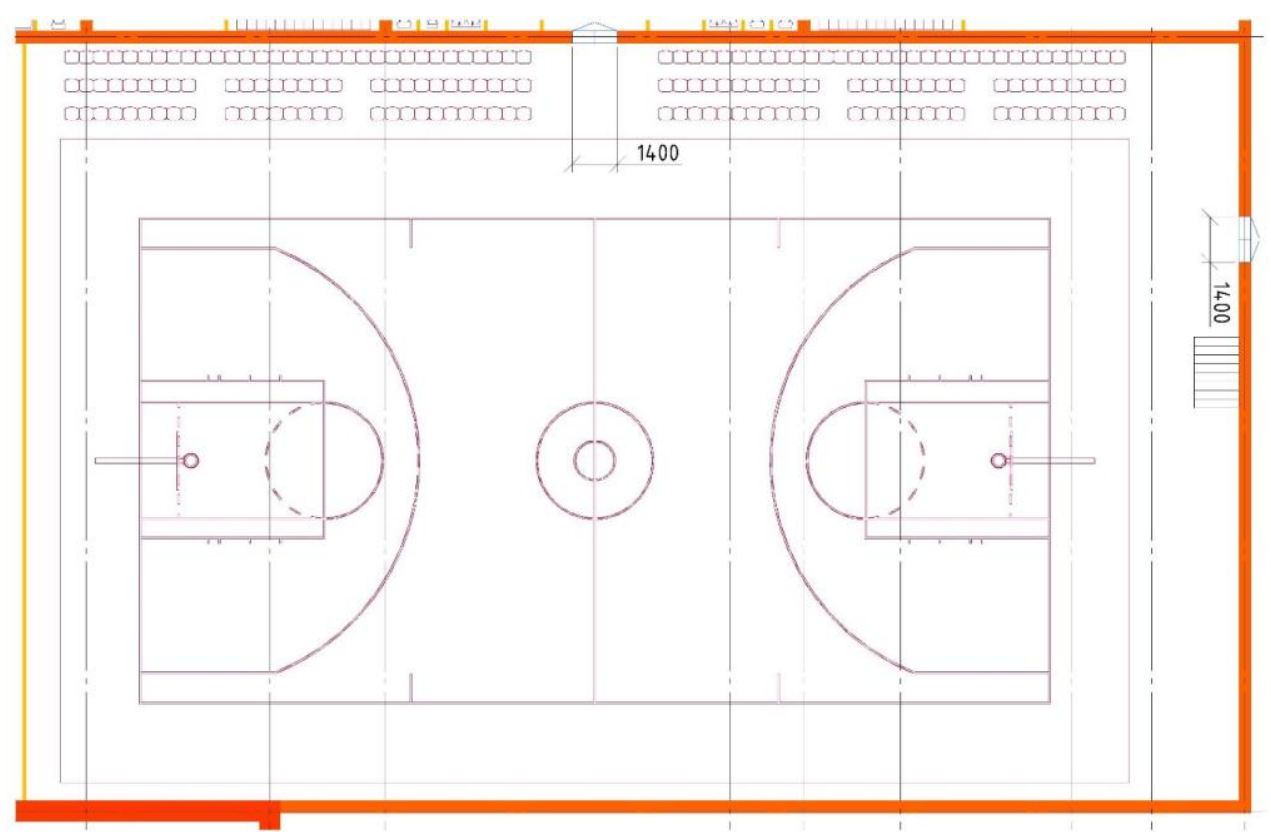

Fig. 1. Scheme of the gym (entry condition).

For the solution of an objective can be used various the space-planning decision. The choice of the best of them is not always obvious. Emergence and development of the fire happens in the conditions of uncertainty. Mistakes when choosing solutions of a problem can lead to catastrophic consequences.

For the solution of problems of the choice of optimal solutions the mathematical apparatus [3], [4], [5] is widely used.

In a solution of the problem of ensuring fire safety various mathematical methods are used: for modeling of systems and processes [6], [7], [8], [9], in the course of monitoring of fire safety requirements [10], on ensuring fire safety at the industrial enterprises [11]. 
One of effective methods of the choice of optimal solutions of a set of alternatives is application of game theory. For optimization of the choice of decisions in the field of fire tactics taking into account a factor of uncertainty the game theory [12], [13] found applications. Application of game theory in the conditions of uncertainty in the specified areas yielded good results. Proceeding from it the conclusion was drawn on expediency of its use for the choice of optimal space-planning solutions of the building for the purpose of ensuring its fire safety.

\section{Methods}

Authors used the section of game theory - a game with the nature, decision-making in the conditions of uncertainty. The choice is caused by lack of reliable information about the probability of emergence of the considered situations. The nature is understood as the generalized concept of the opponent who is not pursuing own aims. The nature can accept one of the possible states.

On the game theory basis (a game with the nature, decision-making in the conditions of uncertainty) the Payoff matrix is under construction (Fig. 2, Table 1) which lines are the strategy of the first player, elements - profits of the player of a which are not payoff of the nature of $\mathrm{B}$.

$A_{i}$-strategy) of player 1

$B_{i}$ - behavior of the player 2 (natures).

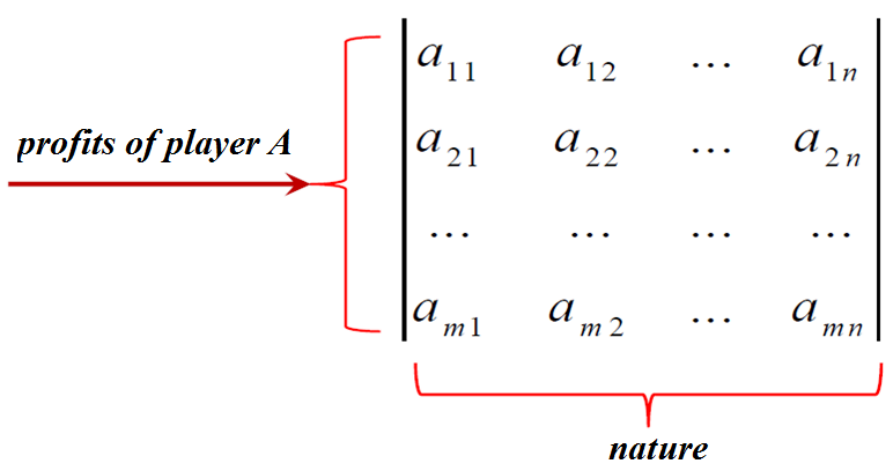

Fig. 2. Payoff matrix.

Table 1. Payoff matrix.

\begin{tabular}{|l|l|l|l|l|}
\hline & $B_{1}$ & $B_{2}$ & & $B_{m}$ \\
\hline$A_{1}$ & $a_{11}$ & $a_{12}$ & $\ldots$ & $a_{1 m}$ \\
\hline$A_{2}$ & $a_{21}$ & $a_{22}$ & $\ldots$ & $a_{2 m}$ \\
\hline$A_{3}$ & $a_{31}$ & $a_{32}$ & $\ldots$ & $a_{3 m}$ \\
\hline & $\ldots$ & $\ldots$ & $\ldots$ & $\ldots$ \\
\hline$A_{n}$ & $a_{n 1}$ & $a_{n 2}$ & $\ldots$ & $a_{n m}$ \\
\hline
\end{tabular}

Apply optimality criterions (alternative optimality criterions) to selection of options of strategy: Wald criterion (2), optimism (3), pessimism (4), Savage (5), Hurwitz (6).

$$
W=\max _{i} \min _{j} a_{i j}
$$




$$
\begin{gathered}
M=\max _{i} \max _{j} a_{i j} \\
P=\min _{i} \min _{j} a_{i j} \\
S=\min _{i} \max _{j} r_{i j} \\
H=\max _{i} \lambda \cdot \max _{j} a_{i j}+\min _{i}(1-\lambda) \cdot \min a_{i j}
\end{gathered}
$$

where $a_{i j}$-element of payoff matrix, $i=1,2, \ldots, n, j=1,2, \ldots, m$.

$r_{i j}$ - element of risc matrix (Table 2),

$\lambda$ - optimism coefficient, $\lambda \in[0,1]$.

Table 2. Risk matrix

\begin{tabular}{|l|l|l|l|l|l|}
\hline & $B_{1}$ & $B_{2}$ & & & $B_{m}$ \\
\hline$A_{1}$ & $r_{11}$ & $r_{12}$ & & $\ldots$ & $r_{1 m}$ \\
\hline$A_{2}$ & $r_{21}$ & $r_{22}$ & & $\ldots$ & $r_{2 m}$ \\
\hline$A_{3}$ & $r_{31}$ & $r_{32}$ & & $\ldots$ & $r_{3 m}$ \\
\hline & $\ldots$ & $\ldots$ & & $\ldots$ & $\ldots$ \\
\hline$A_{n}$ & $r_{n 1}$ & $r_{n 2}$ & & $\ldots$ & $r_{n m}$ \\
\hline
\end{tabular}

Elements of a risk matrix are determined by (8), (9).

$$
\begin{aligned}
& r_{i j}=a_{\max j}-a_{i j} \\
& a_{\max j}=\max \left(a_{i j}\right)
\end{aligned}
$$

The strategy selected according to the greatest number of criteria is optimum.

\section{Results}

Evacuation is timed by a technique [1, appendix 2], and calculation of time of approach of dangerous factors of the fire - agrees [2].

In the analysis of the project documentation of a two-storeyed sports complex on the basis of the techniques stated above by authors it is established that, despite compliance of the project to all standards in the field of fire safety, there is a probability of nonperformance of a condition (1) at evacuation of people from the room of the gym in a case fire emergence.

\section{Statement of the problem:}

In the gym (fig. 1) there are 200 people (the audience, players in the field, judges, etc.). In case of fire alarm all people have to be evacuated before DFF.

The entry condition is defined on the basis of the scheme of the gym (fig. 1).

$A i-$ is the strategy of the player 1

$B i-$ is behavior of the player 2 (natures).

\section{The strategy of the player A:}

- $\mathrm{A}_{1}-$ The project does not change: three doorways $0.8 \mathrm{~m}$ wide. 
- $\mathrm{A}_{2}$ - Increase in width of each of already existing apertures by $0.4 \mathrm{~m}$.

- $\mathrm{A}_{3}$ - The fourth aperture without change of width of apertures is added/

- $\mathrm{A}_{4}$ - Increase in width of each of already existing apertures by $0.4 \mathrm{~m}$ and addition of an aperture $1.8 \mathrm{~m}$ wide

\section{Состояния природы П:}

- $\mathrm{B} 1$ is ignition on a tribune. Time of approach of DFF is equal to $1.6 \mathrm{~min}$.

- $\quad$ B2 is ignition under a staircase without its destruction. Time of approach of DFF is equal to $3 \mathrm{~min}$.

- B3 is ignition under a staircase. Collapse of a staircase and overlapping of one aperture. Time of approach of DFF is equal to $3 \mathrm{~min}$.

Evacuation is timed by a technique [1, appendix No. 2], and calculation of time of achievement of critical values of dangerous factors of the fire pays off according to [2]. Results of calculations are reduced in table 3.

Table 3. Parameters for payoff matrix

\begin{tabular}{|c|c|c|c|c|}
\hline \multirow{3}{*}{ Стратегия } & \multirow{2}{*}{ Параметры } & \multicolumn{3}{|c|}{ Состояние природы } \\
\hline & & $B_{1}$ & $B_{2}$ & $B_{3}$ \\
\hline & $t_{\text {'DFF }}$ (мин) & 1.6 & 3 & 3 \\
\hline \multirow{2}{*}{$\begin{array}{c}A_{1} \\
\delta=1.4 m \\
N=3\end{array}$} & Схема эвакуации & 1 , fig. 2 & 1 , fig. 2 & 2, fig. 3 \\
\hline & $t_{\text {'evacuation }}(\min )$ & 2 & 2 & 2 \\
\hline \multirow{2}{*}{$\begin{array}{c}A_{2} \\
\delta=1.8 m \\
N=3\end{array}$} & Схема эвакуации & 1 , fig. 2 & 1 , fig. 2 & 2, fig. 3 \\
\hline & $t_{\text {evacuation }}(\min )$ & 1.8 & 1.8 & 1.8 \\
\hline \multirow{2}{*}{$\begin{array}{c}A_{3} \\
\delta=1.4 m \\
N=4\end{array}$} & Схема эвакуации & 3 , fig. 4 & 3 , fig. 4 & 4 , fig. 5 \\
\hline & $t_{\text {'evacuation }}(\min )$ & 1.7 & 1.7 & 1.7 \\
\hline \multirow{2}{*}{$\begin{array}{c}A_{4} \\
\delta=1.8 m \\
N=4\end{array}$} & Схема эвакуации & 3 , fig. 4 & 3 , fig. 4 & 4 , fig. 5 \\
\hline & $t_{\text {evacuation }}(\mathrm{min})$ & 1.57 & 1.57 & 1.57 \\
\hline
\end{tabular}

Versions of evacuation schemes are given in fig. 2-5. $\delta$ - width of doorways. 


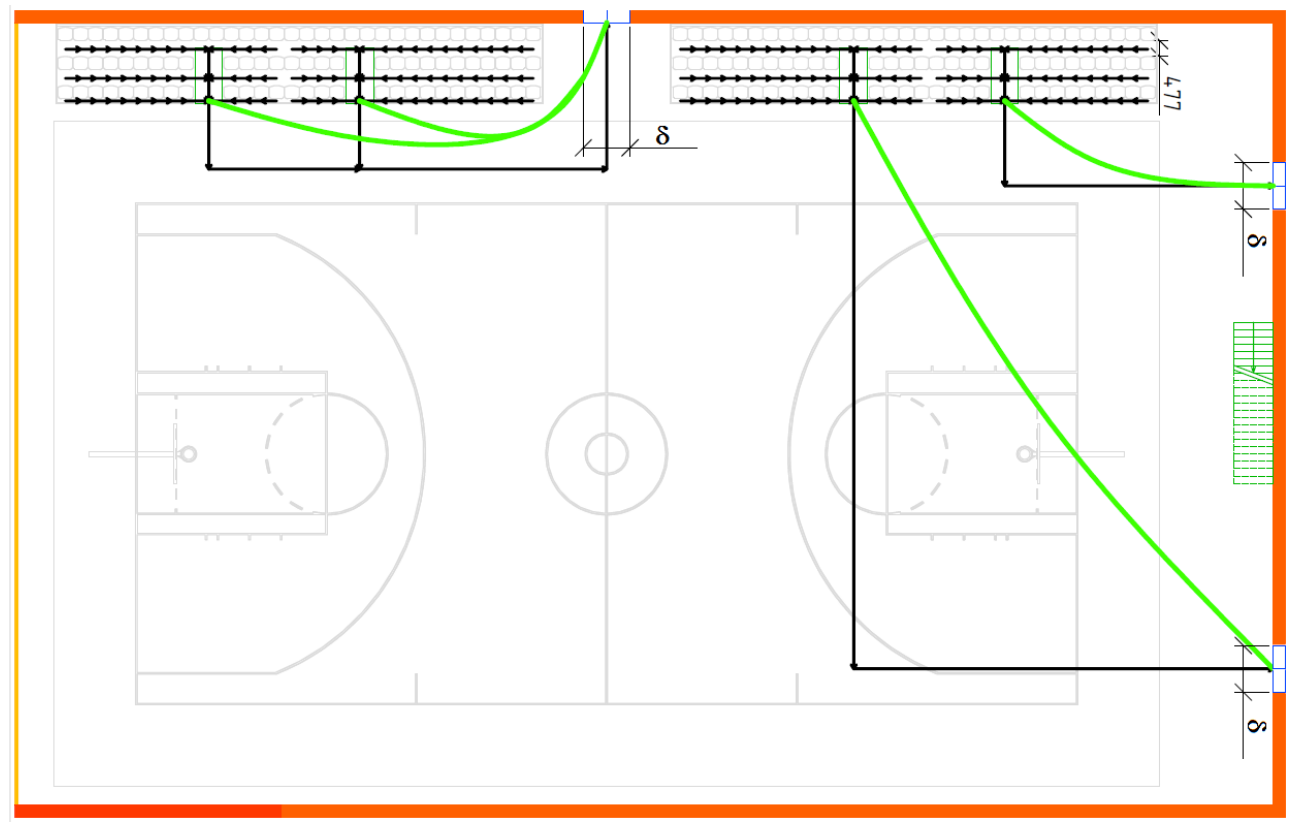

Fig. 2. Scheme of evacuation No 1.

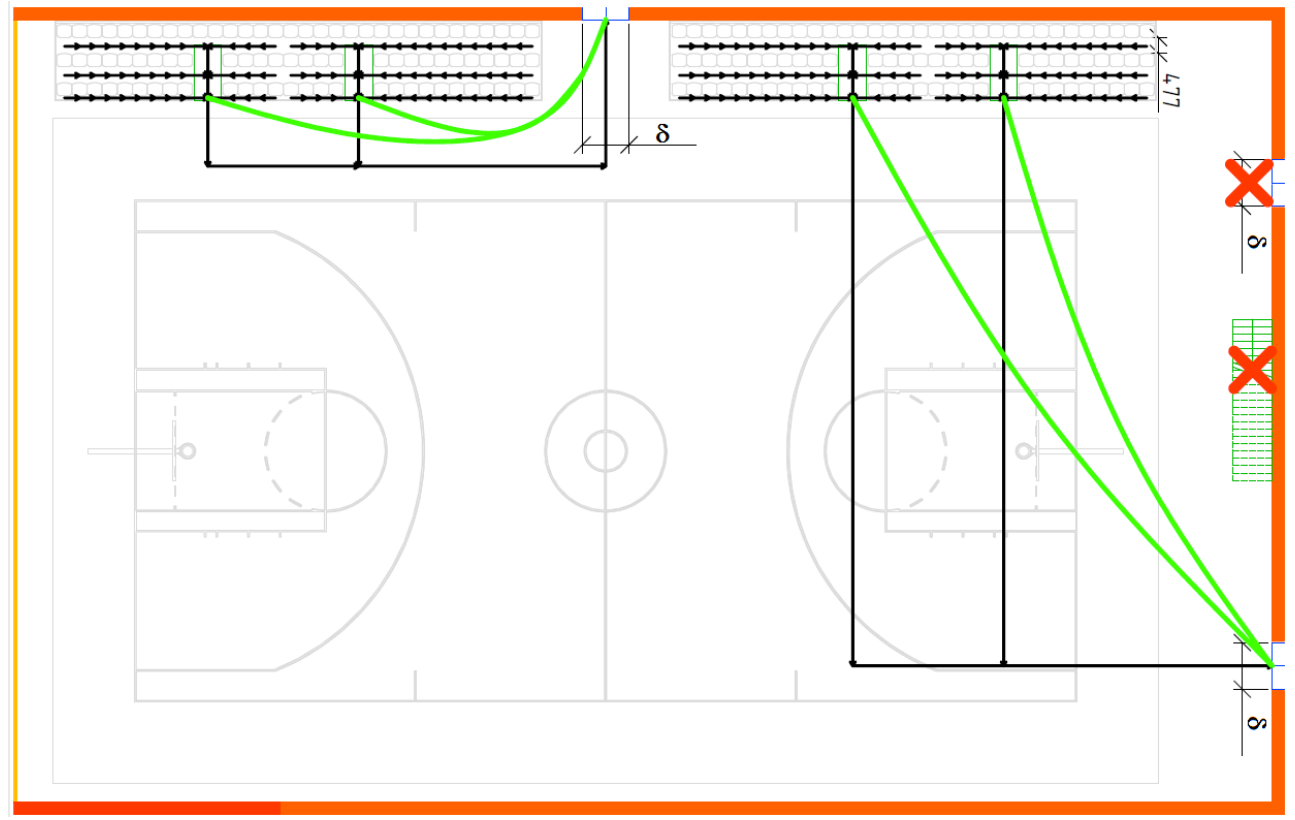

Fig. 3. Scheme of evacuation No 2. 


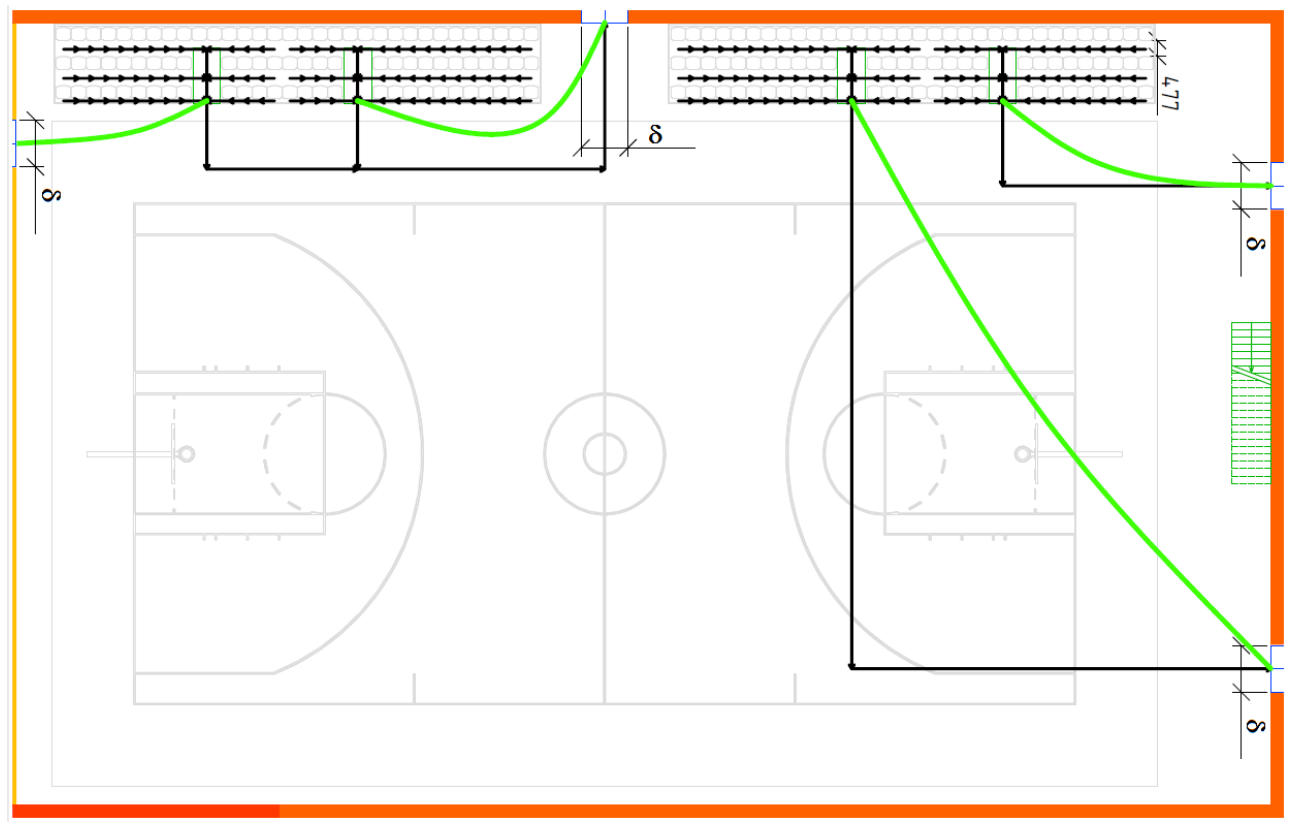

Fig. 4. Scheme of evacuation No 3.

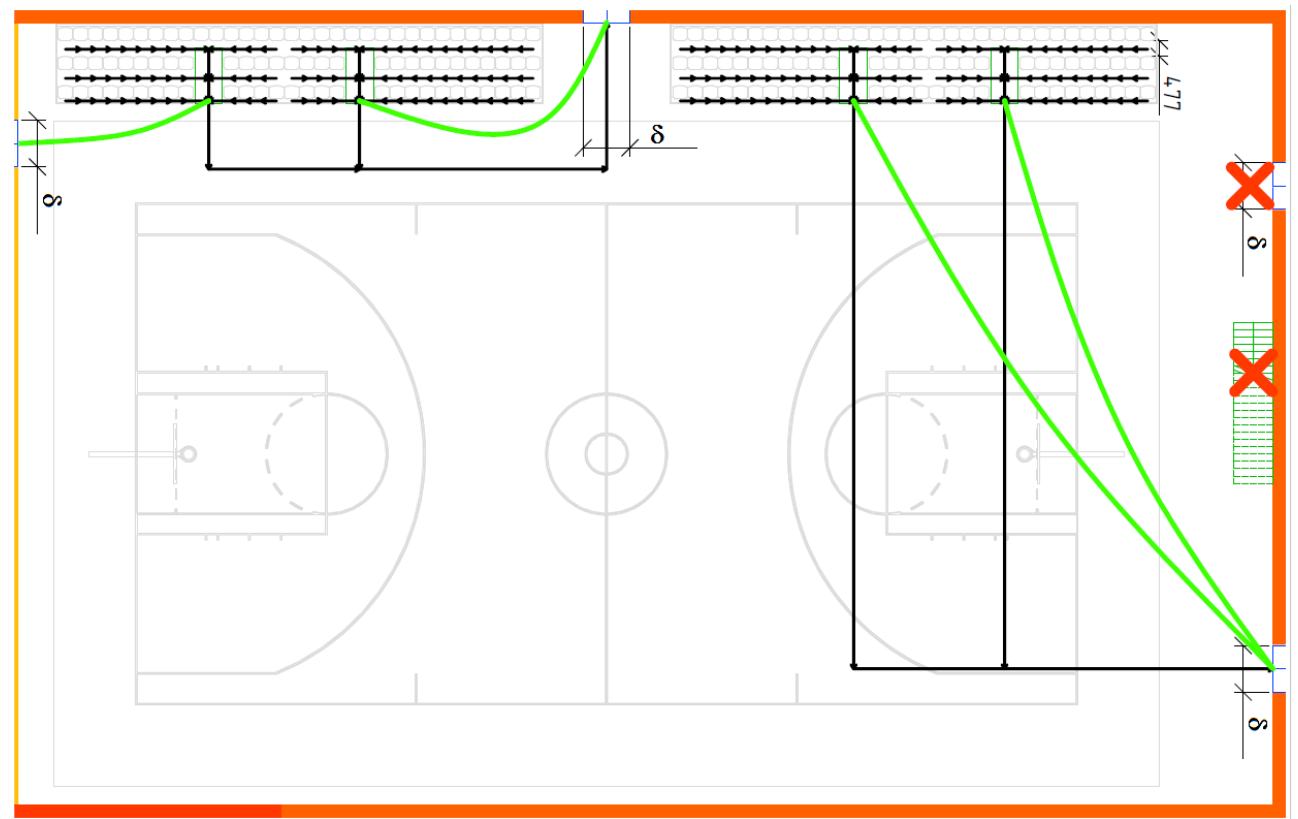

Fig. 5. Scheme of evacuation No 4.

As a profit of the first player of $a_{i j}$ it is decided to use the number of the evacuated people before achievement of critical values of dangerous fire factors. Let's calculate values of elements of a payoff matrix by formula (10). 


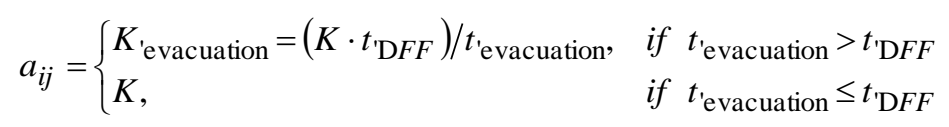

where $K_{\text {'evacuation }}$ is a number of people, in time to be evacuated,

$K=200$ is the number of the evacuated people,

$t^{\prime}$ DFF is time of approach of critical DFF values,

$t$ 'evacuation is evacuation time

We fill payoff matrix with calculation results (table 4).

Table 4. Payoff matrix

\begin{tabular}{|c|c|c|c|}
\hline & $B_{1}$ & $B_{2}$ & $B_{3}$ \\
\hline$A_{1}$ & 160 & 200 & 200 \\
\hline$A_{2}$ & 178 & 200 & 200 \\
\hline$A_{3}$ & 188 & 200 & 200 \\
\hline$A_{4}$ & 200 & 200 & 200 \\
\hline
\end{tabular}

On calculation results on (2)-(9) optimum strategy is $A_{4}$.

\section{Discussion}

In the analysis of the project documentation of a two-storeyed sports complex it was established that despite observance of standards, there is a danger of evacuation delay in case of fire that can entail death of people. For the purpose of ensuring fire safety several versions of space-planning decisions were considered. The analysis of scientific literature showed efficiency of game theory use in the field of fire safety, however in the field of fire safety in construction it was not applied yet. Application of game theory (games with the nature in the conditions of uncertainty) for the solution of the revealed problem was proved.

Three possible scenarios of emergence and development of the fire and four alternative space-planning decisions were considered. For all scenarios of development of the fire time of achievement of critical values of dangerous fire factors was defined. All necessary evacuation schemes are made and calculations are executed. On the calculated parameters basis the payoff matrix was constructed. The payoff matrix' elements were determined as the people number who were in time to be evacuated before achievement by dangerous fire factors of critical values. On the basis of calculation of the payoff matrix for Wald criterion, optimism, pessimism, Savage, Hurwitz an optimal variant of space-planning decisions was chosen. Results of a research showed expediency and efficiency of game theory application in the field of civil engineering fire safety.

\section{Conclusions}

Thus, in work it was shown:

- not always compliance to regulatory requirements can provide the necessary level of fire safety,

- possibility and efficiency of game theory application for the choice of an optimal variant of a solution. 


\section{References}

1. The order of Emercom of Russia of 30.06.2009 No. 382 (an edition of 02.12.2015), About the statement of a technique of determination of rated sizes of fire risk in buildings (2009).

2. Puzach S.V., Andreyev V.V., Methods of calculation of DFF. Methods of forecasting of dynamics of dangerous fire factors, Moscow: Academy of the Public fire service Emercom of Russia (2016).

3. Jonathan Barzilai. Preference Function Modelling: The Mathematical Foundations of Decision Theory, Trends in Multiple Criteria Decision Analysis, pre-print of Chapter 3, pp. 57-86, Springer (2010).

4. Zimmerman H.J., Zysno P. Decisions and evaluations by hierarchical aggregation of information. Fuzzy Sets and Systems, Vol. 10, No 3 - pp. 243-260 (1983)

5. Saaty T.L. Exploring the interface between hierarchical structures. Fuzzy Sets and Systems. Vol. 1, № 1, - p. 57-68 (1978)

6. Sardquist Stefan. An Engineering Approach to Fire-Fighting Tactic, Report 1014, Dept of Fire Safety Engineering, Land Institute of Technology, ISSN 1102-8246, ISRN LUTVDG / TVBB-1014-SE. - 83 p. (1996)

7. Alekhin E.M., Brushlinsky N.N., Sokolov S.V., Wagner P. Russian simulation for strategic planning. "Fire International", 11/1996. - pp. 32-33. (1996)

8. Bruschlinsky N., Nitzschke M., Sokolov S., Wagner P., Feuerwehren in Millionenstaedten. Organisation, Probleme und Loesungen. Stuttgart, Berlin. Koeln,. - pp. 308-310, (1995)

9. Buchanan B.G., Bobrow D., Davis R., Mc Dermott J., Shorlife E.M. Knowledge-based system // Annu. Rep. Computer Science. No 4, - pp. 395-416 (1990).

10. Vechtomov D.A. The information and analytical system of support of adoption of management decisions in the course of monitoring of fire safety requirements, Thesis for: $\mathrm{PhD}$ degree in 05.13.10, M, (2014)

11. Tupikov D.V. Model and algorithms of support of decision-making on ensuring fire safety at the industrial enterprises, Thesis for: $\mathrm{PhD}$ degree in 05.13.01, Saratov, (2015)

12. Teterin I.M., Topolskiy N.G., Klimovtsov V.M., Prus Yu.V., Application of mathematical theory of games in system of support of decision-making. M.: VIPTSH of the Ministry of Internal Affairs of the Russian Federation, 21 p. (2005)

13. Topolsky N.G., Dombrovsky M.B. Bases of application of game theory in automation of fire safety systems. M.: VIPTSH of the Ministry of Internal Affairs of the Russian Federation, 117 p. (1996) 